\title{
Berichtigung \\ zu der Arbeit: Die Polarisation der Resonanzstrahlung des Calciums und ihre Beeinflussung durch schwache Magnetfelder ${ }^{1}$ ).
}

\author{
Von A. Steinhäuser in Gießen.
}

(Eingegangen am 18. Januar 1936.)

In der Formel S. 683 ist fälschlicherweise für $\omega$ die Frequenz eingesetzt worden, während die Kreisfrequenz $\omega=\frac{e}{2 \mathrm{~cm}} \cdot H$ dort stehen mu $\left.\beta^{2}\right)$. Daraus ergibt sich, daß die Werte für die Lebensdauer $\tau$ in Tabelle 2 und 3 noch durch $2 \pi$ zu dividieren sind. Der Mittelwert für die mittlere Lebensdauer des $2{ }^{1} P_{1}$-Zustandes der Ca-Resonanzlinie ergibt sich hiernach zu $\tau=3,5 \cdot 10^{-9} \mathrm{sec}$.

Aus den Messungen über die anomale Dispersion des Ca von Prok ofjew ${ }^{3}$ ) erhält man für die mittlere Lebensdauer $\tau=6,8 \cdot 10^{-9}$ sec, wenn man den von ihm zu 1,16 ermittelten $f$-Wert (Oszillatorenstärke) der Singulettlinie des $\mathrm{Hg}$ für die Resonanzlinie des Ca ebenfalls als richtig annimmt. Die Abweichung des oben gegebenen Wertes für $\tau$ von diesem läßt sich nicht etwa auf den Meßfehler der Polarisationsmessungen zurückführen. Es ist aber immerhin möglich, daß für die Herabsetzung der Lebensdauer das im Resonanzgefäß beigemischte Helium ( $3 \mathrm{~mm}$ Druck) verantwortlich zu machen ist. Einen derartigen Einfluß von zugesetzten Edelgasen konnte v. Ke uss ler $\left.{ }^{4}\right)$ bei $\mathrm{Hg}$ feststellen.

1) ZS. f. Phys. 95, 669, 1935. - ${ }^{2}$ ) Den Hinweis auf dieses Versehen verdanke ich Herrn Hanle. Lis sei bei dieser Gelegenheit darauf hingewiesen, daß3 sich bei P. Pringsheim: Fluoreszenz und Phosphoreszenz im Lichte der neueren Atomtheorie, 3. Aufl., S. 100, derselbe Irrtum findet, ebenso im Handb. d. Phys. XXIII/1., 2. Aufl., S. 203, wo außerdem in der Formel für die Depolarisation im Nenner der Faktor $\pi$ zu viel steht. $-{ }^{3}$ ) W. Prokofjew, ZS. f. Phys. 50, 701, 1928. - ${ }^{4}$ ) V. v. Keussler, Ann. d. Phys. 82, 793, 1927. 